\title{
Thermal performance and redesign of beam stoppers under superficial heat transfer from intense ion beams in matter
}

\author{
André Pilan Zanoni ${ }^{1, *}$, Jose Antonio Briz Monago ${ }^{1}$, and Marco Calviani ${ }^{1}$ \\ ${ }^{1}$ CERN - European Organization for Nuclear Research, Geneva 23, Switzerland
}

\begin{abstract}
In the Linear accelerator 3 (Linac 3) and Low Energy Ion Ring (LEIR) at CERN dedicated beam stoppers intercept ion beams for machine and personnel protection whenever required. The interaction of accelerated ions and the stopper induces through-thickness heat deposition in the stopper material as deep as a few hundreds of micrometers. Following a multi-layered geometrical discretization this paper discusses the thermal and structural performance of the stoppers under different ion beams $(\mathrm{Pb}, \mathrm{Xe}, \mathrm{Ar})$. Design considerations based on the projected range of different ions in target materials (aluminum, steel and copper alloys) are discussed. An improved design for ion stoppers based on thermo-structural performance and projected range is proposed.
\end{abstract}

\section{Nomenclature}

A: number of nucleons per ion

$c_{\mathrm{p}}$ : specific heat capacity

$e$ : elementary charge

$E_{\mathrm{a}}$ : energy per nucleon in $\mathrm{MeV} / \mathrm{n}$

$E_{\text {ion: }}$ energy per ion in $\mathrm{MeV}$

I: current

$l$ : smallest element size

$n_{1}$ : number of layers

$n_{\text {ion }}$ number of ions

$q$ : ion charge

$Q_{\text {ion,max }}$ : maximum deposited heat density per ion

$S_{\mathrm{m}}$ : medium equivalent stress amplitude

$S_{\mathrm{a}}$ : average equivalent stress amplitude

$S_{\mathrm{s}}$ : endurance limit (Soderberg fatigue criterion)

$S_{\mathrm{LF}}$ : yield limit (Soderberg fatigue criterion)

$T_{0}$ : initial temperature

$T_{\text {ad: }}$ adiabatic temperature

$\alpha:$ thermal diffusivity

$\rho$ : density

$\sigma_{\mathrm{x}}, \sigma_{\mathrm{y}}$ : beam sizes at $1 \sigma$ in horizontal and vertical directions respectively

$\sigma_{\mathrm{e}}$ : equivalent von-Mises stress

$\sigma_{\mathrm{y}}(T)$ : temperature-dependent yield strength

$\mu$ : pulse length

\section{Introduction}

The Linear accelerator 3 (Linac 3) and the Low Energy Ion Ring (LEIR) at CERN prepare ion beams to be injected in the Proton Synchrotron (PS) and for the subsequence accelerator chain. In order to protect personnel in case of accidental intrusions in the machine beam stoppers are installed in the accelerator line (Fig. 1).

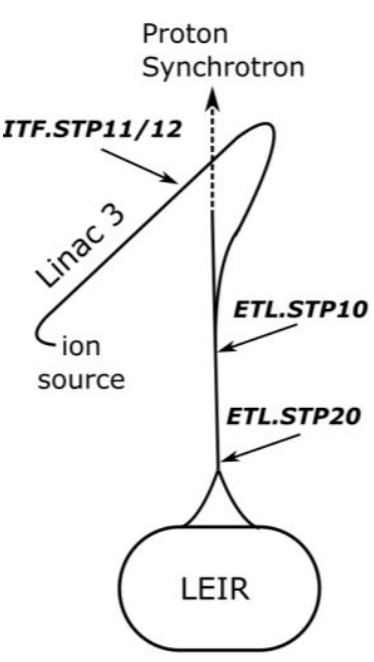

(a)

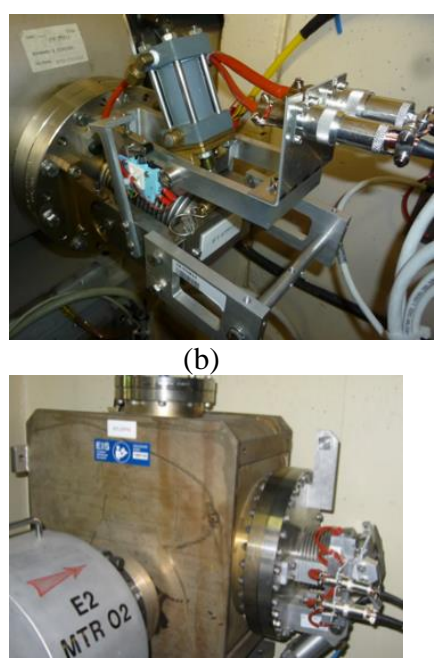

(c)
Fig. 1. (a) Schematic layout of Linac 3 and LEIR. (b) Beam stopper ITF.STP11/12. (c) Beam-stopper type ETL.STP10 and ETL.STP20.

Beam stoppers consist of a material block in vacuum that rests out of the beam line during beam operation. By means of a pneumatic actuator the material block closes - when required - the beam aperture preventing any circulating or unexpected beam to impact downstream areas. The current design of the beam stoppers in Linac 3 and LEIR dates from the early 1990s with limited design documentation available.

When an ion beam at energies of a few tens of $\mathrm{MeV} / \mathrm{n}$ hits the material block heat is shallowly deposited in the block reaching only hundreds of micrometers through-thickness. This heat is the result of the heat transferred from the ion beam momentum, ionization and nuclear interaction processes between

\footnotetext{
*Corresponding author: andre.pilan.zanoni@ cern.ch
} 
beam and matter [1]. For safely designing beam stoppers the material block must withstand the thermal gradients induced by the beam-matter interaction.

The first goal of this paper is to validate the thermal and structural performance of those stoppers through numerical simulation. In this analysis we opt for multilayered discretization of the beam-impact area instead of the time and computationally consuming models with solid elements [2]. Next we propose an improved beam stopper design by analyzing the thermo-structural performance of different targets under ion beam impacts and the projected range of different ions in matter.

\section{Analysis and modeling}

\subsection{Beam operation}

The Linac 3 injects ion beams in LEIR which splits the beam in bunches accelerated from 4.2 to $72 \mathrm{MeV} / \mathrm{n}$ [3]. A typical ion is lead, although xenon is also employed in the CERN physics program [4]. In the past the facility ran other ions such as oxygen, indium, argon and helium [5].

Table 1 shows critical beam scenarios for the analysis of the ion beam stoppers at injection energies of 4.2 MeV/n. The lead ion refers to ${ }^{208} \mathrm{~Pb}^{54+}$, the xenon ion to ${ }^{129} \mathrm{Xe}^{39+}$ and the argon ion to ${ }^{40} \mathrm{Ar}^{11+} . \sigma_{\mathrm{x}}$ and $\sigma_{\mathrm{y}}$ correspond to beam sizes at $1 \sigma$ following a planar Gaussian distribution in horizontal and vertical directions respectively.

Table 1. Beam parameters for ion beam stoppers at injection [5].

\begin{tabular}{cccccc}
\hline $\begin{array}{c}\text { Beam } \\
\text { stopper }\end{array}$ & Ion & $\begin{array}{c}\text { Current } \\
{[\mu \mathrm{A}]}\end{array}$ & $\begin{array}{c}\text { Ion } \\
\text { energy* } \\
{[\mathrm{MeV}]}\end{array}$ & $\begin{array}{c}\sigma_{\mathrm{x}} \\
{[\mathrm{mm}]}\end{array}$ & $\begin{array}{c}\sigma_{\mathrm{y}} \\
{[\mathrm{mm}]}\end{array}$ \\
\hline ITF & $\mathrm{Pb}$ & 50 & 874 & 4.3 & 6.9 \\
& $\mathrm{Xe}$ & 50 & 542 & 4.3 & 6.9 \\
& $\mathrm{Ar}$ & 62 & 168 & 4.3 & 6.9 \\
\hline ETL & $\mathrm{Pb}$ & 50 & 874 & 5.9 & 10.3 \\
& $\mathrm{Xe}$ & 50 & 542 & 5.9 & 10.3 \\
& $\mathrm{Ar}$ & 62 & 168 & 5.9 & 10.3 \\
\hline$* E_{\text {ion }=A . E_{\mathrm{a}}}$ & & & &
\end{tabular}

The beam stoppers can receive beam at injection energies over four continuous weeks following two scenarios. In the first scenario the beam has a $200 \mu \mathrm{s}$ long pulse repeated each $0.2 \mathrm{~s}$. The second scenario considers $600 \mu \mathrm{s}$ long pulses spaced by $0.4 \mathrm{~s}$.

In rare accidental scenarios an extracted pulse of lead ions at $72 \mathrm{MeV} / \mathrm{n}$ from LEIR might hit the stopper ETL.STP20. The accidental pulse has two bunches, each $200 \mathrm{~ns}$ long spaced by $354 \mathrm{~ns}$. The number of ions per pulse is $3 \times 10^{9}$ with $\sigma_{\mathrm{x}}=5.0 \mathrm{~mm}$ and $\sigma_{\mathrm{y}}=4.5 \mathrm{~mm}$.

\subsection{Beam-matter interaction}

We simulate the interaction between ion beams and the stopper block using the Monte Carlo FLUKA code [1, 6], a particle transport and interaction code. The block is divided in energy bins in which the energy deposited is normalized to one ion.

At low energies the ions come to a complete stop in the block material due to strong ionization losses $[1,6]$.

\subsection{Geometrical and thermal modeling}

The material block in the stopper ITF.STP11/12 is a 10 mm thick stainless steel plate. In ETL.STP10 and 20 the absorbing block is made of aluminum alloy Antico 100 with $\varnothing 200 \mathrm{~mm}$ and $210 \mathrm{~mm}$ length. None of them is actively cooled, with only radiation to vacuum chambers and heat conduction through supports being the only heat sinks. Figure 2 and Fig. 3 present the geometrical model and meshing of both absorbers.

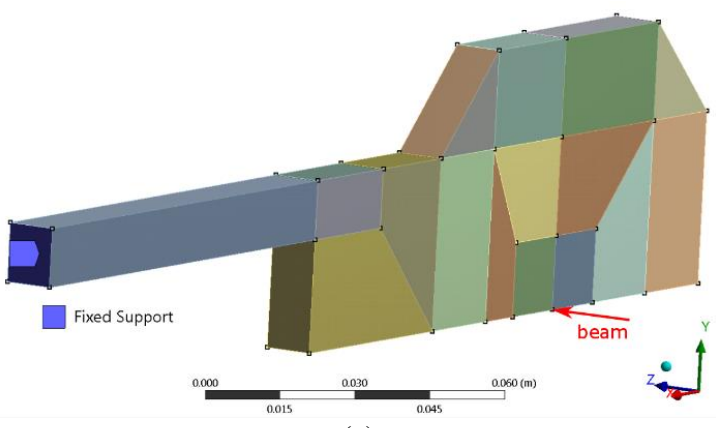

(a)

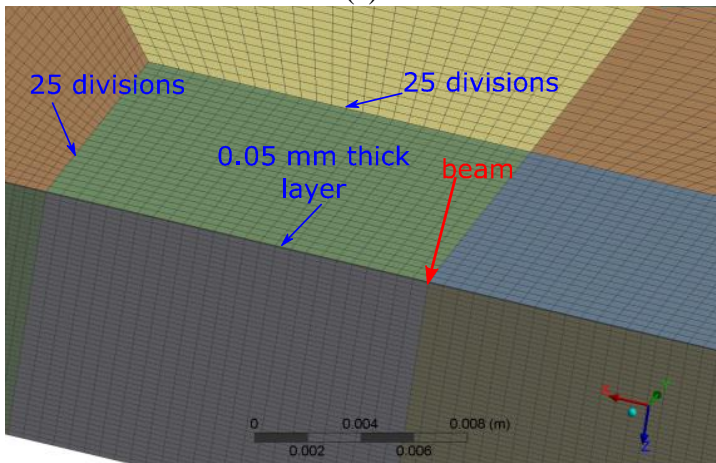

(b)

Figure 2. ITF absorber: (a) geometrical model divided in mesh zones. The XZ plane is used for symmetry. (b) Meshing near the beam impact.

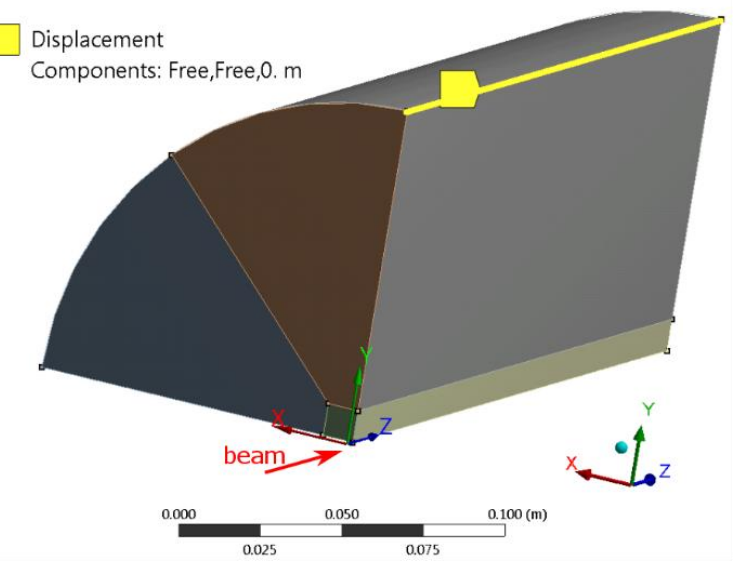

(a) 


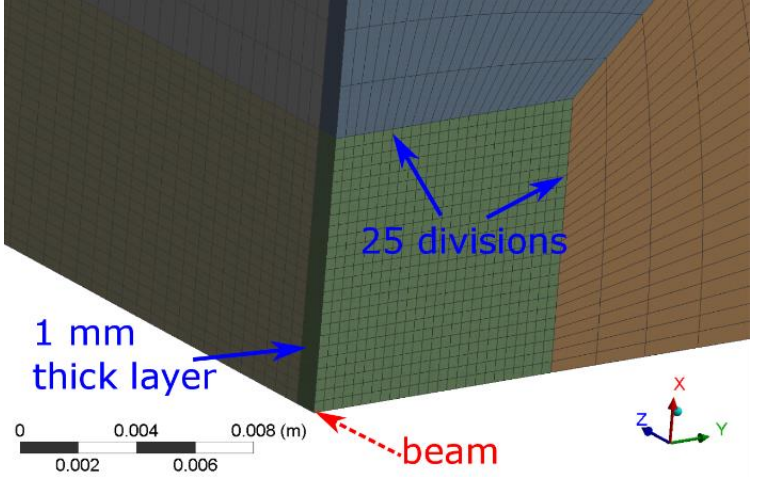

(b)

Fig. 3. ETL absorber: (a) geometrical model divided in mesh zones. The $\mathrm{XZ}$ and $\mathrm{ZY}$ planes are used for symmetry. The yellow edge is not allowed to displace in $Z$ direction. (b) Meshing near the beam impact.

The projected range of $4.2 \mathrm{MeV} / \mathrm{n}$ lead ions is $20 \mu \mathrm{m}$ in stainless steel [Fig. 4(a)] and $46 \mu \mathrm{m}$ in Antico 100. To discretize the very tight energy deposition throughthickness we opt for a multi-layered discretization of the area impacted by the beam following [Fig. 4(b)] [2].

In ANSYS 17.1 we model this area with layered shell elements and couple them with regular solid elements. This method allows accurate layer-wise application of heat generation, greatly reducing the total amount of elements [2]. We use up to 30 layers for the multilayered discretization.

Steady-state and transient-thermal models are solved in ANSYS 17.1 [7]. To guarantee correct initial timestep resolution we implement initial time steps smaller than $l^{2} /(4 \alpha)[8]$.

For the beam injection scenarios we simulate the four-week beam operation through a steady-state analysis in which the heat generation is averaged by the pulse repetition rate (Fig. 5). We use the steady-state temperatures as the initial condition to a transientthermal analysis for modeling one steady pulse averaging the heat generation by the pulse length.

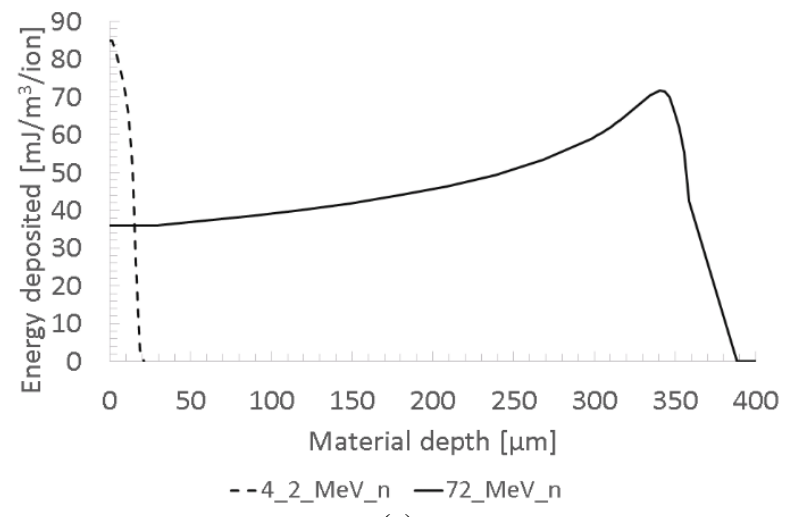

(a)

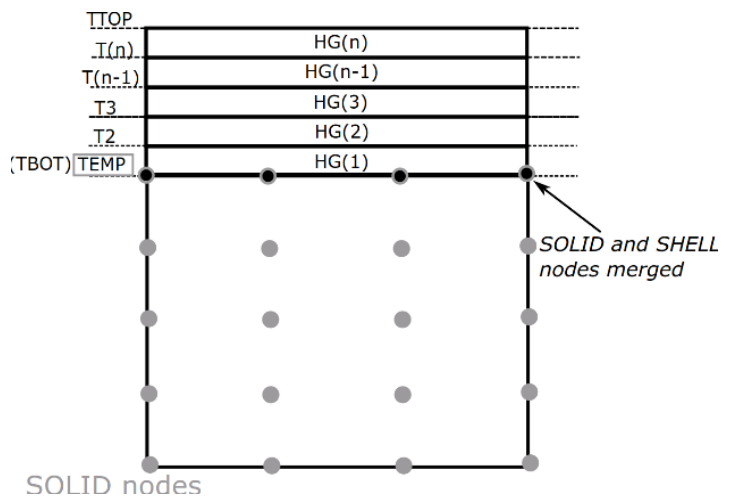

(b)

Fig. 4. (a) Projected range of lead ions at $4.2 \mathrm{MeV} / \mathrm{n}$ and 72 $\mathrm{MeV} / \mathrm{n}$ in stainless steel $[1,6]$. (b) Schematic representation of the multi-layered discretization of the geometrical model [2].

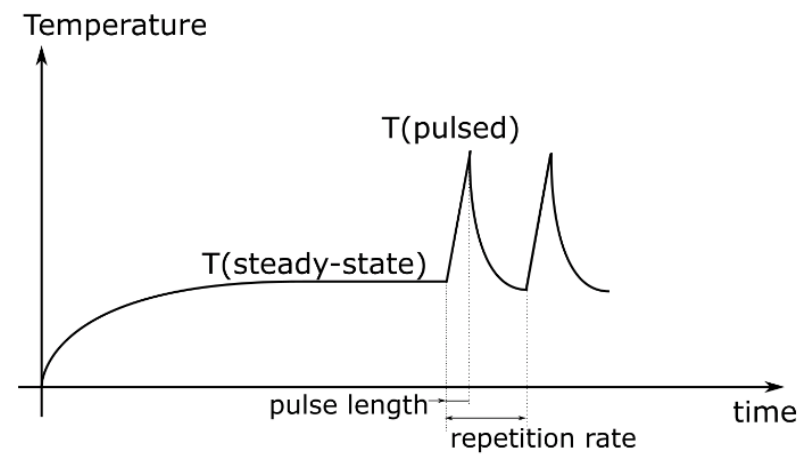

Fig. 5. Schematic representation of the steps for thermal modeling of beam injection scenarios.

For both stopper blocks a radiation emissivity of 0.1 from the outer core surfaces is implemented. For the ITF stopper block we implement a total heat conductance through the screws of $300 \mathrm{~W} /\left(\mathrm{m}^{2} \mathrm{~K}\right)$, comparable to the one adopted in Ref. [9]. The initial temperature of both stoppers is assumed to be homogeneous at $22^{\circ} \mathrm{C}$.

The equivalent stresses induced by the thermal gradients are calculated using the von-Mises yield criterion [10]. Considering the temperature-dependent yield strength as the structural limit, $\sigma_{\mathrm{e}} / \sigma_{\mathrm{y}}(\mathrm{T})<1$ indicates the thermal deformation is reversible, otherwise it is permanent.

\section{Results and discussion}

\subsection{Projected range of ions in matter}

Table 2 presents the results of the range of argon, xenon and lead ions at 4.2 and $72 \mathrm{MeV} / \mathrm{n}$ in the aluminum alloy Antico 100 and stainless steel. Note that the range in matter is inversely proportional to the material density.

The range of the light argon ion in the ITF stainless steel block is $1 \mathrm{~mm}$, shorter than the block thickness of $10 \mathrm{~mm}$. In the ETL block out of Antico 100 the longest ion range $(2.56 \mathrm{~mm})$ is still much shorter than the total block length $(210 \mathrm{~mm})$. Both blocks completely stop the primary ion beams having overdimensioned block lengths. 
In the thermal analysis we adjust the thickness of the layered-element shell according to each ion-matter scenario.

Table 2. Projected range of ions in matter via SRIM [11].

\begin{tabular}{cccc}
\hline Ion & $\begin{array}{c}\text { Ion } \\
\text { energy } \\
{[\mathrm{MeV} / \mathrm{n}]}\end{array}$ & $\begin{array}{c}\text { Range in } \\
\text { stainless steel } \\
{[\mu \mathrm{m}]}\end{array}$ & $\begin{array}{c}\text { Range in } \\
\text { Antico 100 } \\
{[\mu \mathrm{m}]}\end{array}$ \\
\hline Lead & 4.2 & 20 & 46 \\
Xenon & 4.2 & 17 & 39 \\
Argon & 4.2 & 17 & 39 \\
\hline Lead & 72 & 382 & 980 \\
Xenon & 72 & 433 & 1100 \\
Argon & 72 & 1000 & 2560 \\
\hline
\end{tabular}

\subsection{Heat diffusivity and model verification}

Because of long energy deposition rates of hundreds of microseconds and the tight projected ranges heat can easily diffuse in the material during beam impacts. In order to quantify submillimetric heat diffusion in the stopper blocks we compare the maximum adiabatic temperature with the maximum actual temperature in the block for one beam impact.

We calculate the adiabatic temperature at the position of maximum heat density deposition per ion $\left(Q_{\mathrm{ion}, \max }\right)$ in matter calculated via FLUKA using Eq. 1. In order to validate the heat import to the thermal model in ANSYS 17.1 we run a transient analysis of one beam impact in the material block with nearly zero diffusivity by setting the material thermal conductivity to $10^{-10} \mathrm{~W} /(\mathrm{mK})$.

$$
T_{\text {ad }}=\frac{Q_{\text {ion } \max } n_{\text {ion }}}{\rho c_{\mathrm{p}}}+T_{0}
$$

The number of ions is calculated through Eq. 2.

$$
n_{\text {ion }}=\frac{I \mu}{e|q|}
$$

We perform another transient analysis of one beam pulse impact now with the actual material thermal conductivity. We compare the maximum temperature of both transient analyses.

Table 3 presents the results for lead ions at injection energy in the ITF and ETL blocks with a pulse length of $200 \mu \mathrm{s}$. Note that the hypothetical adiabatic temperatures serve only to present the effect of heat diffusion and validating thermal results. The adiabatic temperatures in both models have a maximum difference of $1.7 \%$.

Table 3. Maximum adiabatic and actual temperatures of lead ions in ITF and ETL stoppers. Initial block temperature: $22^{\circ} \mathrm{C}$.

\begin{tabular}{cccc}
\hline $\begin{array}{c}\text { Stopper } \\
\text { block }\end{array}$ & \multicolumn{2}{c}{ Adiabatic $\left[{ }^{\circ} \mathrm{C}\right]$} & Actual $\left[{ }^{\circ} \mathrm{C}\right]$ \\
& $\begin{array}{c}\text { FLUKA } \\
\text { model }\end{array}$ & $\begin{array}{c}\text { Thermal } \\
\text { model }\end{array}$ & $\begin{array}{c}\text { Thermal } \\
\text { model }\end{array}$ \\
\hline ITF $($ steel $)$ & 47.2 & 47.0 & 33.5 \\
ETL $(\mathrm{Al})$ & 39.5 & 39.2 & 24.4 \\
\hline
\end{tabular}

Turning on heat diffusion effects we estimate the actual peak temperature rise in the ITF steel block is 2.2 times smaller than the adiabatic results. Heat diffusion is stronger in the ETL aluminum-alloy block being 7.2 times smaller than the adiabatic result.

\subsection{Thermo-structural performance}

We discuss the performance of ion beam stoppers at injection and extraction energies.

\subsubsection{Injection}

Table 4 presents the maximum temperature in the stopper blocks for one beam pulse after steady state for different ions and beam-pulse setups. Although the block receives repeated beam during four continuous weeks thermal steady state is reached in few minutes. Fig. 6 shows the steady-state temperature distribution in the ITF and ETL blocks under repeated lead ion impacts with $0.2 \mathrm{~s}$ pulse repetition rate.

Table 4. Maximum temperatures for injection scenarios. Pulse length in brackets.

\begin{tabular}{cccccc}
\hline $\begin{array}{c}\text { Stopper } \\
\text { block }\end{array}$ & Ion & \multicolumn{2}{c}{$0.2 \mathrm{~s}(200 \mu \mathrm{s})$} & \multicolumn{2}{c}{$0.4 \mathrm{~s}(600 \mu \mathrm{s})$} \\
ITF & $\mathrm{Pb}$ & 31.9 & 43.1 & 37.3 & 57.1 \\
& $\mathrm{Xe}$ & 30.5 & 37.0 & 34.7 & 48.6 \\
& $\mathrm{Ar}$ & 32.8 & 38.5 & 38.0 & 49.7 \\
\hline ETL & $\mathrm{Pb}$ & 22.3 & 24.7 & 22.4 & 30.3 \\
\hline
\end{tabular}

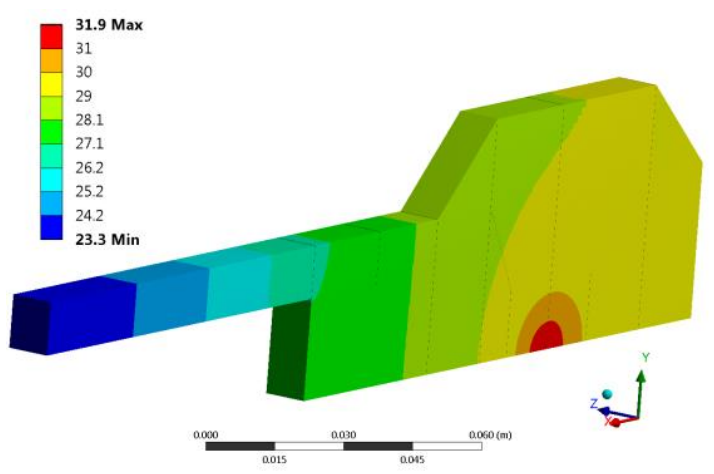

(a)

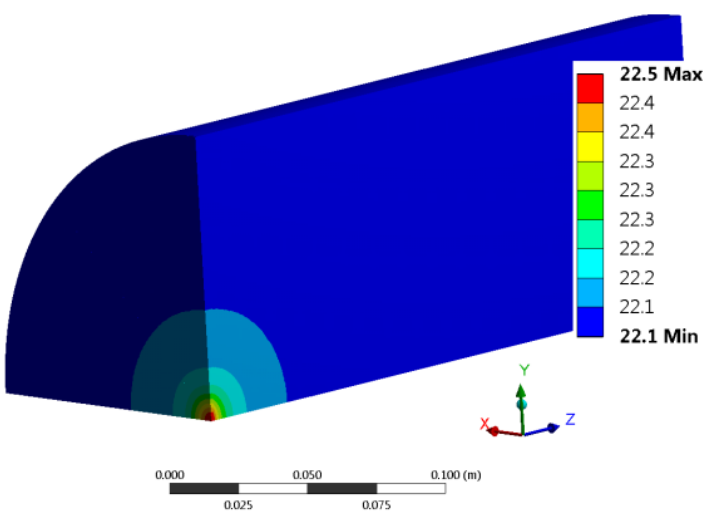

(b)

Fig. 6. Steady-state results for injection scenarios of lead ions with a repetition rate of $0.2 \mathrm{~s}$ in ${ }^{\circ} \mathrm{C}$ : (a) ITF block. (b) ETL block. 
We skip the analysis on the ETL stopper block under xenon and argon ions as only very small temperature variations are expected.

The ion beam scenario with $0.4 \mathrm{~s}$ pulse repetition rate and $600 \mu \mathrm{s}$ pulse length induces the highest stresses in both ITF and ETL blocks. The maximum equivalent stress in the ITF steel block is $86.7 \mathrm{MPa}$ corresponding to $\max \sigma_{\mathrm{e}} / \sigma_{\mathrm{y}}(T)=0.55$. In ETL the maximum equivalent stress is $19.0 \mathrm{MPa}$ with $\max \sigma_{\mathrm{e}} / \sigma_{\mathrm{y}}(T)=0.08$. We take temperature-dependent yield strengths from [12] for stainless steel and [13] for Antico 100.

\subsubsection{Extraction}

We combine the two bunches of an extracted ion beam in one single pulse with $400 \mathrm{~ns}$ pulse length. Because of this short pulse length heat deposition is faster than heat diffusion in the block. We calculate a difference of $1.0 \%$ between the peak adiabatic temperature and the actual peak temperature from the thermal model.

A single lead pulse induces a maximum temperature of $59.4^{\circ} \mathrm{C}$ and a maximum equivalent stress of $78.1 \mathrm{MPa}$ in the ETL block, corresponding to $\max \sigma_{\mathrm{e}} / \sigma_{\mathrm{y}}(T)=0.33$. The maximum temperature and stresses are $45.5^{\circ} \mathrm{C}$ and 50.4 $\mathrm{MPa}$ for xenon and $28^{\circ} \mathrm{C}$ and $13.1 \mathrm{MPa}$ for argon.

\section{Redesign of the ion beam stoppers}

Although the absorbing blocks of both ITF and ETL stoppers withstand all possible beam impact scenarios we investigate a compact stopper design for both ITF and ETL lines with thinner blocks.

\subsection{Beam stopper design}

With the objective of harmonizing the design of beam stoppers with those of similar devices at CERN we study the compatibility of a small size beam stopper design from ELENA (Extra Low Energy Antiproton) [14] adapted to Linac 3 and LEIR (Fig. 7).

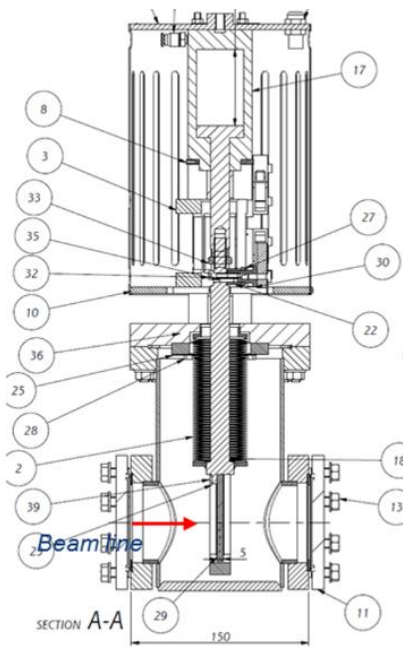

(a)

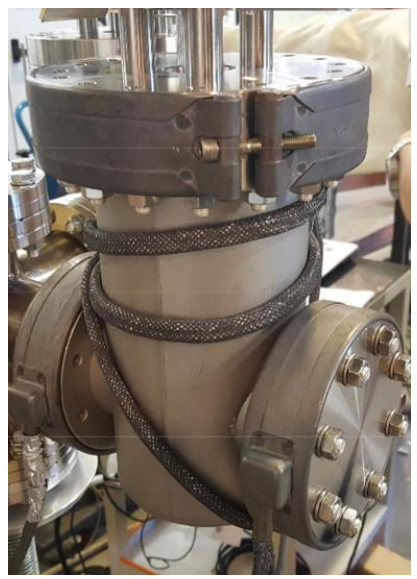

(b)
Fig. 7. ELENA beam stopper: (a) cut view [15]. (b) unit ready for installation at company CINEL, Italy.
The absorbing block consists of a stainless steel plate with $\varnothing 83 \mathrm{~mm}$ and $5 \mathrm{~mm}$ thickness. However an extracted lead ion beam already induces a maximum temperature of $78.3^{\circ} \mathrm{C}$ and a maximum equivalent stress of $154 \mathrm{MPa}$ and $\max \sigma_{\mathrm{e}} / \sigma_{\mathrm{y}}(T)=1.01$, exceeding the yield strength of stainless steel.

Maintaining the same ELENA-type beam stopper design the plate can be replaced by any geometry with $\varnothing$ $83 \mathrm{~mm}$ and a maximum thickness of $20 \mathrm{~mm}$.

\subsection{Proposed materials for block absorbers}

The absorber material must have good thermal conductivity to attenuate thermal gradients caused by continuous beam impacts at injection energies over four weeks. In order to allow the LEIR machine to run a wide range of ions at extraction energies the absorbing block must completely stop the lightest ion, which is helium.

From a thermo-structural perspective aluminum is a strong material candidate. However the project range of helium in aluminum is $20.6 \mathrm{~mm}$, which is longer than the allowed thickness for the ELENA-type stopper.

Another alternative is a copper-based material. We choose $\mathrm{CuCr} 1 \mathrm{Zr}$, a copper-alloy with superior mechanical resistance and similar thermal properties as pure copper [16]. Knowing the projected range of helium ions $\left({ }^{4} \mathrm{He}^{2+}\right)$ at $72 \mathrm{MeV} / \mathrm{n}$ in this alloy is $7.5 \mathrm{~mm}$ we analyze the thermo-structural performance of a $10 \mathrm{~mm}$ thick $\mathrm{CuCr} 1 \mathrm{Zr}$ block under both injection $(4.2 \mathrm{MeV} / \mathrm{n})$ and extraction ( $72 \mathrm{MeV} / \mathrm{n})$ beam scenarios.

\subsection{Performance of a CuCr1Zr block}

Considering thermal cooling through radiation to the vacuum chamber $(\varepsilon=0.1)$ and poor heat conductance through supports of $25 \mathrm{~W} /\left(\mathrm{m}^{2} \mathrm{~K}\right)$ [17] we analyze the beam injection scenario of lead ions continuously hitting the block over four weeks. We choose the worst-case beam scenario with $0.4 \mathrm{~s}$ pulse repetition rate and $600 \mu \mathrm{s}$ pulse length. For some pulses after steady state the minimum and maximum temperatures in the block are 106.7 and $135.0^{\circ} \mathrm{C}$ respectively. This temperature distribution yields a maximum equivalent stress of 73.2 $\mathrm{MPa}$ and $\max \sigma_{\mathrm{e}} / \sigma_{\mathrm{y}}(T)=0.28$.

In order to assess the fatigue behavior of the new block we apply the Soderberg criterion (Eq. 3) [18]. The material is safe if $F>1$

$$
F=\frac{1}{\left(\frac{S_{\mathrm{m}}}{S_{\mathrm{g}}}+\frac{S_{\mathrm{g}}}{S_{\mathrm{LF}}}\right)}>1
$$

The number of cycles over four weeks is $1.2 \times 10^{7}$ for a beam pulse with the shortest repetition rate. We consider $S_{\mathrm{m}}=S_{\mathrm{a}}=36.6 \mathrm{MPa}, S_{\mathrm{S}}=90 \mathrm{MPa}$ for this cycle range [19], and $S_{\mathrm{LF}}=0.7 \sigma_{\mathrm{y}}(T)=185 \mathrm{MPa}$ at $\mathrm{T}=140^{\circ} \mathrm{C}$. The plate does not reach any fatigue limit as $F=5.1$.

An extracted beam pulse of lead ions from LEIR induces a maximum temperature of $86^{\circ} \mathrm{C}$ and max $\sigma_{\mathrm{e}} / \sigma_{\mathrm{y}}(T)=0.49$ (Fig. 8). The maximum energy deposition, temperature and equivalent stresses in the 
stopper lie in the beam axis. The temperature peaks at $320 \mu \mathrm{m}$.

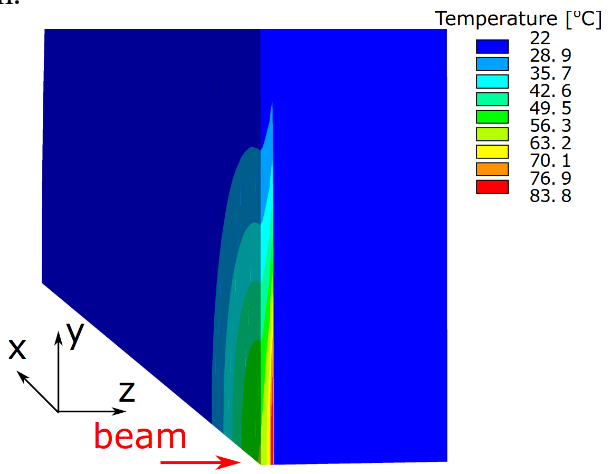

(a)

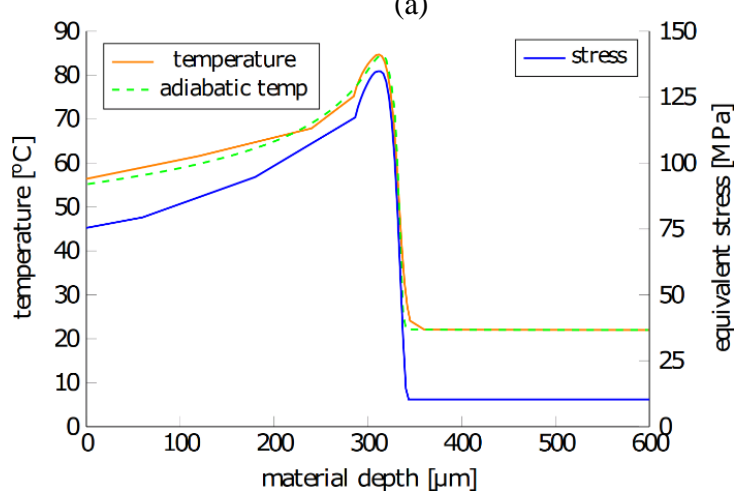

(b)

Fig. 8. (a) Thermal distribution stopper block out of $\mathrm{CuCr} 1 \mathrm{Zr}$ after one extracted ion beam pulse from LEIR [2]. (b) Thermal and equivalent-stress distribution in the beam axis [2].

\section{Conclusions}

We validated the thermo-structural performance of beam stoppers under shallow energy deposition from intense ion beams in stopper targets at Linac 3 and LEIR. Taking into account short ranges of ion in matter from $17 \mu \mathrm{m}$ to $2.56 \mathrm{~mm}$ we discretized the beam-impact zone with multi-layered elements. To verify this method we calculated a maximum temperature difference of less than $1.7 \%$ between the multi-layered and adiabatictemperature calculations.

We analyzed the stoppers under long-term ion injection at 4.2 MeV/n and one-pulse extraction scenario at $72 \mathrm{MeV} / \mathrm{n}$. For all ion beam configurations none of the targets reach structural limits. The most critical scenario was the impact of injected lead ions in the ITF stainless steel block over four continuous weeks inducing max $\sigma_{\mathrm{e}} / \sigma_{\mathrm{y}}(T)=0.55$.

Although the ion stoppers withstand all beam configurations we proposed a compact beam stopper for both Linac 3 and LEIR, replacing the $210 \mathrm{~mm}$ long block at ETL. The new stopper block consists of a copper-alloy disc with $\varnothing 83 \mathrm{~mm}$ and $10 \mathrm{~mm}$ thickness. It withstands continuous impacts of $4.2 \mathrm{MeV} / \mathrm{n}$ lead ions with $0.4 \mathrm{~s}$ pulse repetition rate and $600 \mu \mathrm{s}$ pulse length over four weeks as well as one extracted lead ion at 72 $\mathrm{MeV} / \mathrm{n}$ with a pulse length of $400 \mathrm{~ns}$. We designed the stopper block thicker than the range of the lightest ion in the copper alloy, allowing Linac 3 and LEIR to run any ion with mass number from 4 (helium) to 208 (lead).
The authors want to thank Richard Scrivens for beam operation data and Sven de Man for the design data on the ELENA-type beam stoppers.

\section{References}

[1] A. Ferrari, P. R Sala, A. Fasso, J. Ranft, FLUKA: A multi-particle transport code (Program version 2005, Stanford, CA 94309, 2005)

[2] A. Pilan Zanoni, Phys. Rev. Accel. Beams, 21, 5, p.054801 (2018)

[3] S. Gilardoni, D. Manglunki et al, Fifty years of the CERN Proton Synchrotron (CERN, 2013)

[4] D. Manglunki et al, CERN's Fixed Target Primary Ion Programme (International Particle Accelerator Conference, Busan, Korea, 2016)

[5] R. Scrivens, "Beam Parameters from Linac3 to LEIR for Beam stoppers,” 2017.

[6] T. Boehlen et al, Nuclear Data Sheets, 120, pp.211214 (2014)

[7] ANSYS Academic Research, Release 17.1 (manual).

[8] R. Stout, P. D. Billings and PEON Semiconductors, Accuracy and time resolution in thermal transient finite element analysis, (ANSYS-TM Users Conference, 2002)

[9] J. J. Scialdone, C. H. Clatterbuck, J. L. Wall, Thermal conductance of two interface materials and their applications in space systems, (NASA Technical Memorandum 104554, March 1992)

[10] R. v. Mises, Nachrichten von der Gesellschaft der Wissenschaften zu Goettingen, MathematischPhysikalische Klasse, 1913, 4, pp.582-592 (1913)

[11] J. F. Ziegler, M. D. Ziegler, J. P. Biersack, Nuclear Instruments and Methods in Physics Research Section B: Beam Interactions with Materials and Atoms, 268, 11-12, pp.1818-1823 (2010)

[12] J. F. Dempsey et al, Challenges in Mechanics of Time-Dependent Materials and Processes in Conventional and Multifunctional Materials, 2, pp.7-15 (2013)

[13] Pechinery group, Aluminium - semi-finished products (Paris: Edition Pechiney Rhenalu, 1997)

[14] D. Horvath, FLUKA calculations for AD beam stopper design (CERN - EDMS 1529712, 2015)

[15] Drawing H1AB0100 (company CINEL, Italy), 2015-2017.

[16] D. Kupferinstitut, Kupferdatenblatt $\mathrm{CuCr} 1 \mathrm{Zr}$, (Deutsches Kupferinstitut, Duesseldorf, Germany, 2005)

[17] J. E. Fontenot Jr, The Thermal Conductance of Bolted Joints (Louisiana State University (LSU Historical Dissertations and Theses) 1968)

[18] E. Iurzolla, I criteri di resistenza, Cortina, 1991.

[19] CES Selector 2017, CERN. 